\title{
Decision complacency and conservation planning
}

Charlie J. Gardner ${ }^{*}$, Patrick O. Waeber ${ }^{2}$, Onja H. Razafindratsima ${ }^{3,4,5}$, Lucienne Wilmé $e^{6,7}$

${ }^{1}$ Durrell Institute of Conservation and Ecology, University of Kent, Canterbury, Kent CT2 7NR, U.K. ${ }^{2}$ Forest Management and Development, Department of Environmental Sciences, Swiss Federal Institute of Technology Zurich, Universitätsstrasse 16, ETH Zentrum, 8092 Zurich, Switzerland.

${ }^{3}$ Department of Biosciences, Rice University, Houston, Texas, TX 77005, USA.

${ }^{4}$ Department of Organismic and Evolutionary Biology, Harvard University, Cambridge, MA 02138, USA

${ }^{5}$ Department of Biology, College of Charleston, Charleston, SC 29424, USA

${ }^{6}$ Missouri Botanical Garden, Madagascar Research and Conservation Program, Lot VP 31, Anjohy Ankadibevava, BP 3391, Antananarivo 101, Madagascar.

${ }^{7}$ World Resources Institute, 10 G St. NE Suite 800, Washington, D.C. 20002

* email c.gardner-399@kent.ac.uk

Running title: Decision Complacency

Impact statement: Conservation planners must use systematic decision-making tools and evidence to guide their decisions. 
Conservation science evolved to inform the practice of conserving biodiversity, yet a widespread researcher-practitioner divide limits the application of science to conservation action. For example, it is widely recognized that the research produced by conservation scientists rarely satisfies the information needs of conservation practitioners and decision makers, who are thus unable to make sufficiently evidence-based decisions (Milner-Gulland et al. 2010; Laurance et al. 2012; O’Connell \& White 2017). However, this situation tells only half the story because decision makers themselves may not seek or use evidence to make their decisions, even when it is available, or test the impacts of their actions. Sutherland and Wordley (2017) recently termed this latter phenomenon evidence complacency.

We agree that not using evidence results in suboptimal decision making and risks undermining the ability to meet conservation goals. However, we suggest bad decision making can still occur in conservation even when evidence is used. Once collected and synthesized, evidence must be transformed into decisions through some form of decisionsupport system to frame the decision context and process the evidence in a systematic and transparent manner that minimizes the influence of the decision makers' cognitive biases (Segan et al. 2011; Dicks et al. 2014). Because this critical step is not captured by the concept of evidence complacency, we propose the term decision complacency be used in its stead and define it as the nonuse of evidence or systematic processes to make decisions. We illustrate our argument with the example of a high-profile, recent conservation plan for a taxonomic group of global conservation priority, Madagascar's lemurs.

The Lemur Conservation Strategy 2013-2016 (Schwitzer et al. 2013) was an "emergency conservation action plan" (Schwitzer et al. 2014) seeking to "prevent the extinction of all 
lemur species in the next decade and ensure their long term survival"' (Schwitzer et al. 2013). Developed by 60 lemur scientists and conservationists during a workshop in Antananarivo in 2012, its principal outputs included a selection of 30 priority sites or site clusters at which conservation efforts should be concentrated and the elaboration of site-specific action plans. Both outputs were informed by evidence (Schwitzer et al. 2013). Nevertheless, we argue that suboptimal decisions were made because no decision-support systems were used to process that evidence systematically.

The site prioritization was informed by empirical evidence, including lemur species richness, number of endangered or critically endangered lemur species (IUCN 2014), and whether a site harbored the only known population of a species (Schwitzer et al. 2013). Nevertheless, no systematic approaches were used either to establish a comprehensive pool of potential sites or select the final priority list. To assess the performance of the prioritization, we produced a simple species-occurrence spreadsheet with data from Schwitzer et al. (2013) and the Noe4D database, a database of over 50, 000 faunal locality records in Madagascar derived from museum specimens and the peer-reviewed literature (Waeber et al. 2017). Only 91\% of the 101 lemur species were represented in the 30 priority sites, whereas one-third of sites showed redundancy in that they only conserved species already represented in the selection (Fig. 1, Supporting Information). Although redundancy provides additional protection for represented species, it reduces the chances of conserving every species within a limited selection of sites. Representation could have been increased from $91 \%$ to $96 \%$ by replacing any 2 redundant sites with Ampasindava and Antafondro and to 99\% through the substitution of any 7 redundant sites with those containing unrepresented species. 
Action plans for priority sites were based on a different form of evidence -expert knowledge of participants with site-specific experience - although again no systematic approaches were employed to process that evidence into decisions. The resulting strategies may be effective, but they are unlikely to be as effective as they might have been had a systematic approach been used to list all potential actions, gather evidence about them, and objectively evaluate the likely effectiveness of each (Segan et al. 2011). Action planning may additionally have been informed by its 1992 predecessor, Lemurs of Madagascar: an Action Plan for Their Conservation (Mittermeier et al. 1992), following a process of monitoring and evaluation. No such process was undertaken.

The nonuse of decision-support tools means that, in effect, both the site prioritisation and site action plans were developed on the basis of expert judgment. Expert knowledge is of course necessary to produce any such conservation plan; however, expert judgments and decisions may be influenced by a range of cognitive biases if elicited without the use of rigorous methods (Drescher et al. 2013; Sutherland \& Burgman 2015). Furthermore, there is high potential for consciously or unconsciously self-serving decision making when the decisions will determine which project sites, study sites, or conservation approaches (such as protectedarea establishment, community-based management, taxonomic research, captive breeding, or conservation education) are prioritized for future funding. If funds are to be optimally allocated, decision making should be based on systematic and transparent processes to objectively identify priority sites and evaluate the relative strengths of proposed strategies, rather than the subjective judgment of those with a vested interest in the funding of particular actions and places (Pedrono 2011). 
We understand decision makers often lack empirical data and may rely on multiple forms of evidence, including experience, intuition, and expert judgment (Cook et al. 2012; Martin et al. 2012), and that conservation plans must be developed rapidly in the face of great uncertainty and are necessarily pragmatic in approach. However, a range of tools and approaches for systematic conservation decision making (CDM) have been developed to ensure that whatever evidence is available - including expert judgment - is rigorously, objectively, and systematically treated to promote optimal decision making (Bower et al. 2017; Schwartz et al. 2017). For example, systematic conservation planning facilitates site prioritizations that maximize species representation at least cost and can incorporate a range of additional (e.g. social and economic) data layers beyond simple species distributions (Margules \& Pressey 2000; McIntosh et al. 2017). Tools such as the Open Standards for Conservation (CMP 2013) utilize conceptual models to promote the objective selection of the strategies most likely to succeed in reducing threats and meeting stated objectives. Although both approaches are somewhat technical, this should not preclude their use to make decisions in real-world conservation contexts. Capacity for systematic conservation planning is widespread in Madagascar and the Open Standards are routinely used in management planning for the country's protected areas. These and equivalent CDM tools can be rapidly applied in workshop settings (Gregory et al. 2012; Di Fonzo et al. 2017), and we strongly recommend their use in all conservation planning if funds are to be allocated optimally.

The Lemur Conservation Strategy 2013-2016 is important because it increased awareness of the lemur conservation crisis, helped in fund raising, and stimulated action. However, we suggest that the systematic use of CDM approaches would have resulted in outputs better suited to its goal of conserving all lemur species. Although we have highlighted a single case study, the problems we identified are likely to be widespread wherever conservation 
decisions are made without the involvement of those with CDM experience. Although a range of tools and approaches have been developed to promote good decision making, they are not always used when they are needed most, in the real-world allocation of scarce conservation funds. Understanding why decision makers do not always make the best decisions depends on correctly recognizing and characterizing the problem, and in this respect we believe the term decision complacency better encapsulates the multiple facets of conservation decision making than Sutherland and Wordley's (2017) alternative. We hope that by recognizing this issue we encourage conservation decision makers to make better use of existing evidence and CDM capacity and to start developing a culture of systematic decision making in conservation.

\section{Acknowledgments}

This research was supported by the Swiss Programme for Research on Global Issues for Development under the research grant IZ01Z0_146852 as part of the AlaReLa Alaotra Resilience Landscape project. We are grateful to B. Ferguson, I. Tattersall, 4 anonymous reviewers, and participants in a discussion forum on the Madagascar Environmental Justice Network for comments and discussions that contributed to some of the ideas in this article.

\section{Supplementary Information}

The database of lemur occurrence records used for Fig. 1 (Appendix S1) is available online. The authors are solely responsible for the content and functionality of these materials. Queries (other than absence of the material) should be directed to the corresponding author.

\section{Literature Cited}

section not edited carefully 
Bower SD, Brownscombe JW, Birnie-Gauvin K, Ford MI, Moraga AD, Pusiak RJP, Turenne ED, Zolderdo AJ, Cooke, SJ, Bennett, JR. 2017. Making tough choices: picking the appropriate conservation decision-making tool. Conservation Letters 11: (e12418) DOI: 10.1111/conl.12418.

CMP (Conservation Measures Partnership). 2013. The open standards for the practice of conservation. Version 3.0. Conservation Measures Partnership. Available from http://cmpopenstandards.org/ (accessed October 2017).

Cook CN, Carter RW, Fuller RA, Hockings M. 2012. Managers consider multiple lines of evidence important for biodiversity management decisions. Journal of Environmental Management 113: 341-346.

Dicks LV, Walsh JC, Sutherland WJ. 2014. Organising evidence for environmental management decisions: a '4S' hierarchy. Trends in Ecology \& Evolution 29: 607-613.

Di Fonzo MMI, Nicol S, Possingham HP, Flakus S, West JG, Failing L, Long G, Walshe T. 2017. Cost-effective resource allocator: a decision support tool for threatened species management. PARKS 23: 101-113.

Drescher M, Perera AH, Johnson CJ, Buse LJ, Drew CA, Burgman MA. 2013. Towards rigorous use of expert knowledge in ecological research. Ecosphere 4: article 83. DOI: $\underline{10.1890 / \mathrm{ES} 12-00415.1}$ 
Gregory R, Failing L, Harstone M, Long G, McDaniels T, Ohlson D (Eds.). 2012. Structured decision making: a practical guide to environmental management choices. Wiley-Blackwell, Oxford.

IUCN (International Union for Conservation of Nature). 2014. Guidelines for using the IUCN Red List categories and criteria, Version 11. IUCN, Gland.

Laurance WF, Koster H, Grooten M, Anderson AB, Zuidema PA, Zwick S, Zagt RJ, Lynam AJ, Linkie M, Anten NPR. 2012. Making conservation research more relevant for conservation practitioners. Biological Conservation 153: 164-168.

Margules CR, Pressey RL. 2000. Systematic conservation planning. Nature 405: 243-253.

Martin TG, Burgman MA, Fidler F, Kuhnert PM, Low-Choy S, McBride M, Mengersen K. 2012. Eliciting expert knowledge in conservation science. Conservation Biology 26: 29-38.

McIntosh E, Pressey RL, Lloyd S, Smith RJ, Grenyer R. 2017. The impact of systematic conservation planning. Annual Review of Environment and Resources 42: 677-697.

Milner-Gulland EJ, Fisher M, Browne S, Redford KH, Spencer M, Sutherland WJ. 2010. Do we need to develop a more relevant conservation literature? Oryx 44: 1-2.

Mittermeier RA, Konstant WR, Nicoll ME, Langrand O. 1992. Lemurs of Madagascar: an action plan for their conservation 1993-1999. IUCN/SSC Primate Specialist Group, Gland. 
O’Connell M, White R. 2017. Academics can also be culprits of evidence complacency. Nature Ecology \& Evolution 1: 1589.

Pedrono M. 2011. Wasted efforts: why captivity is not the best way to conserve species. Madagascar Conservation \& Development 6: 57-59.

Schwartz MW, Cook CN, Pressey RL, Pullin AS, Runge MC, Salafsky N, Sutherland WJ, Williamson MA. 2017. Decision support frameworks and tools for conservation. Conservation Letters 11: (e12385) DOI: 10.1111/conl.12385.

Schwitzer C, Mittermeier RA, Davies N, Johnson S, Ratsimbazafy J, Razafindramanana J, Louis Jr EE, Rajaobelina S. 2013. Lemurs of Madagascar: a strategy for their conservation 2013-2016. IUCN, Gland.

Schwitzer C, Mittermeier RA, Johnson SE, Donati G, Irwin M, Peacock H, Ratsimbazafy J, Razafindramanana J, Louis Jr EE, Chikhi L et al. 2014. Averting lemur extinctions amid Madagascar's political crisis. Science 343: 842-843.

Segan DB, Bottrill MC, Baxter PWJ, Possingham HP. 2011. Using conservation evidence to guide management. Conservation Biology 25: 200-202.

Sutherland WJ, Burgman MA. 2015. Use experts wisely. Nature 526: 317-318.

Sutherland WJ, Wordley CFR. 2017. Evidence complacency hampers conservation. Nature Ecology \& Evolution 1: 1215-1216. 
Waeber PO, Gardner CJ, Lourenço WR, Wilmé L. 2017. On specimen killing in the era of conservation crisis - a quantitative case for modernizing taxonomy and biodiversity inventories. PLoS ONE 12 (e0183903) DOI: 10.1371/journal.pone.0183903 
SSG and follow color-figure policies and procedures.

Figure 1. Lemur species richness and uniqueness at selected sites across Madagascar (red, 30 priority sites or site clusters for lemur conservation selected in the Lemur Conservation Strategy [Schwitzer et al. 2013]; blue, other protected areas in Madagascar's protected-area system that are not priority sites for lemur conservation). Pie charts show lemur species richness (each slice represents 1 species) and the uniqueness of the species recorded at that site (the darker the slice, the fewer priority sites in which it occurs). Blue pie charts contain species unrepresented in the original prioritization (dark blue slices). 'Gain' refers to the number of priority sites at which species would occur if these blue sites were included in the priority list. 